\title{
Transnuclear mice with pre-defined T Cell Receptor specificities against Toxoplasma gondii obtained via SCNT
}

\author{
Oktay Kirak $^{1,4}$, Eva-Maria Frickel ${ }^{1}$, Gijsbert M. Grotenbreg ${ }^{1,3}$, Heikyung Suh ${ }^{1}$, Rudolf \\ Jaenisch $^{1,2,4}$, and Hidde L. Ploegh ${ }^{1,2,4}$ \\ ${ }^{1}$ Whitehead Institute for Biomedical Research, Cambridge, MA 02142 \\ ${ }^{2}$ Department of Biology, Massachusetts Institute of Technology, Cambridge, MA 02142
}

\section{Abstract}

\begin{abstract}
Mice transgenic for rearranged antigen-specific $\mathrm{T}$ cell receptors (TCR) are essential tools to study $\mathrm{T}$ cell development and function. Such TCRs are usually isolated from the relevant T cells after longterm culture, often following repeated antigen stimulation, which unavoidably skews the $\mathrm{T}$ cell population used. Random genomic integration of the TCR $\alpha$ - and $\beta$-chain and expression from nonendogenous promoters represent additional drawbacks of transgenics. Using epigenetic reprogramming via somatic cell nuclear transfer, we demonstrate that $\mathrm{T}$ cells with pre-defined specificities against Toxoplasma gondii can be used to generate mouse models that express the TCR from their endogenous loci, without experimentally introduced genetic modification. The relative ease and speed with which such transnuclear models can be obtained holds promise for the construction of other disease models.
\end{abstract}

\begin{abstract}
The resolution of an infectious disease requires careful orchestration of innate and adaptive immunity. B and T cells specific for infectious agents are not easily obtained in abundant and pure form, yet their availability is crucial in defining their activation requirements and protective properties, either as a single clone or as an ensemble of different specificities. During the peak of an immune response as many as $30 \%$ of all $\mathrm{CD}^{+} \mathrm{T}$ cells may be pathogen-specific $(1,2)$. For viral pathogens such as vaccinia virus or mouse herpes virus-68, several dozen antigens may be recognized by $\mathrm{CD} 8^{+}$and $\mathrm{CD}^{+} \mathrm{T}$ cells (3-5). Existing $\mathrm{T}$ cell receptor transgenic mouse models have all been constructed from $\mathrm{T}$ cell clones or hybridomas selected for survival and response to antigens in vitro. Whether these transgenic mouse models accurately reflect the affinities and activation requirements of lymphocytes triggered during a physiological response to an infection is not known.

Somatic cell nuclear transfer (SCNT) allows the generation of ES cells and mice from any somatic cell through epigenetic reprogramming without the introduction of genetic modifications (6-8). The specificity of T or B cell receptors (TCR or BCR) is determined by site-specific recombination of their V, D and J gene segments. Consequently, when SCNT is applied to lymphocytes of known specificity, these genetic $\mathrm{V}(\mathrm{D}) \mathrm{J}$ rearrangements are transferred to the SCNT-embryonic stem cells (ESCs) and the mice derived from them, while epigenetic marks are reset (Fig. 1A). Natural Killer T cells (NKT) carrying an invariant TCR, as well as T and B cells of unknown specificity, have been used as donor cells for SCNT,
\end{abstract}

\footnotetext{
${ }^{4}$ Correspondence: Oktay Kirak, Whitehead Institute for Biomedical Research, Cambridge, MA 02142, USA, kirak@wi.mit.edu Rudolf Jaenisch, Whitehead Institute for Biomedical Research, Cambridge, MA 02142, USA, jaenisch@ wi.mit.edu Hidde L. Ploegh, Whitehead Institute for Biomedical Research, Cambridge, MA 02142, USA, ploegh@wi.mit.edu.

${ }^{3}$ Current address: National University of Singapore, Immunology Programme and Departments of Microbiology and Biological Sciences, 117456 Singapore
} 
demonstrating that mice can be cloned from such cells and that their rearranged TCR- or Igloci can be transmitted through the germline (9-12).

Here we apply this approach to create new mouse model by using effector $\mathrm{CD} 8^{+} \mathrm{T}$ cells specific for Toxoplasma gondii, isolated at the height of resolving an acute infection. We focused on these cells because protective immunity against this protozoan critically depends on interferon (IFN)- $\gamma$ produced by $\mathrm{CD} 8^{+} \mathrm{T}$ cells $(13,14)$. We had identified two naturally processed epitopes, $\mathrm{L}^{\mathrm{d}}-\mathrm{Tg}-\mathrm{Rop} 7^{161-169}(\mathrm{R} 7)$ and $\mathrm{L}^{\mathrm{d}}-\mathrm{Tg}-\mathrm{Gra} 4^{107-115}(\mathrm{G} 4)$, restricted by the major histocompatibility complex antigen (MHC-I) $\mathrm{H}-2 \mathrm{~L}^{\mathrm{d}}$ and recognized by $\mathrm{CD} 8^{+} \mathrm{T}$ cells (15). Using a similar approach, a screen for epitopes recognized by $\mathrm{H}-2 \mathrm{~K}^{\mathrm{b}}$ or $\mathrm{H}-2 \mathrm{D}^{\mathrm{b}}$ let to the identification of one epitope restricted by $\mathrm{H}-2^{\mathrm{b}}, \mathrm{K}^{\mathrm{b}}-\mathrm{Tg}$-tgd057 $7^{59-66}$ (T57) a protein of unknown function, likely to be secreted (16). One additional H-2d epitope, $\mathrm{L}^{\mathrm{d}}-\mathrm{Tg}-\mathrm{Gra6}{ }^{215-224}$, was identified in parallel (17). However, there has been no mouse model that provides access to naïve antigen-inexperienced $T$. gondii-specific $\mathrm{T}$ cells.

We used CD8 ${ }^{+} \mathrm{T}$ cells specific for R7, G4, and T57 on the BL/6 × Balb/c F1 (B6CF1) background as donor cells for SCNT, a procedure that is more efficient for donor nuclei of mixed background (6). We used Trichostatin A (TSA), an inhibitor of histone deacetylases, to improve nuclear reprogramming (Fig. 1B). We generated SCNT-blastocysts with an overall efficiency of 7.2\% per pseudo-pronucleus (PPN) in all three conditions, and obtained ESCs when using TSA treatment for 6h (4 ESC lines) or 10h (1 ESC line), but none in the absence of TSA. As a control, fertilized blastocysts on the B6CF1 background yielded 47 ESCs per 48 blastocysts (fig. S1A). When $\mathrm{CD} 8^{+} \mathrm{T}$ cells from a pure Balb/c background were used as donor cells, we derived 2 SCNT-ESC lines with similar efficiency (fig. S1B), but only after 10h TSA treatment, confirming reports that TSA indeed facilitates cloning of inbred mice $(7,18)$.

We generated chimeric mice using the five SCNT-ESC lines from the B6CF1 background, all of which showed pronounced populations of tetramer-positive $\mathrm{CD} 8^{+} \mathrm{T}$ cells in the absence of infection with $T$. gondii (Fig. 1C). Chimeric mice derived from the two SCNT-ESC lines on the Balb/c background also yielded $\mathrm{CD} 8^{+} \mathrm{T}$ cells of correct specificity (fig. S1C). We thus cloned $\mathrm{T}$ cells of desired specificity in seven out of seven cases, a rate that depends on both TSA treatment and the ability to obtain donor cells of sufficient purity. We refer to these animals as transnuclear (TN) mice because such mice, generated via SCNT of T cells (or B cells) with pre-selected specificity, represent a new type of mouse model.

To test for germline transmission and to establish TN mouse lines, chimeric mice with T57 T cells $\left(\mathrm{H}-2^{\mathrm{b}}\right.$ restricted) were backcrossed onto the MHC-matched BL/6 background. Offspring with agouti coat color indicated germline-transmission (fig. S1D). Chimeric mice with $\mathrm{H}-2^{\mathrm{d}}$ restricted T cells (G4 and R7) were backcrossed onto the MHC-matched Balb/c background and offspring with white coat color indicated germline transmission (fig. S1D). All litters from transmitting males were analyzed either by PCR or flow cytometry to identify offspring carrying the corresponding TCR (fig. S1E-G). We secured germline transmission of the respective TCRs in five out of five SCNT-ESC lines derived from the B6CF1 background. No germline transmission was achieved for the two SCNT-ES cell lines from the Balb/c background. The resulting animals represented three different TCR specificities (T57, G4, and $\mathrm{R} 7)$, restricted by two different MHC-I alleles $\left(\mathrm{H}-2 \mathrm{~L}^{\mathrm{d}}\right.$ and $\left.\mathrm{H}-2 \mathrm{~K}^{\mathrm{b}}\right)$.

We next identified the genomic TCR rearrangements from the TN mice on the B6CF1 background (Fig. 2A, fig. S2A-B) by RACE-PCR. Examination of the cDNA sequences obtained showed that the three SCNT-ESC lines specific for R7 were different from each other. A comparison of their amino acid sequences revealed no obvious pattern of the complementary determining region 3 (CDR3) that would explain their shared specificity (fig. S2C). 
To characterize TN mice, we compared splenocytes from the T57 line with B6CF1 wildtype mice and a widely used TCR transgenic line also restricted by $\mathrm{H}-2 \mathrm{~K}^{\mathrm{b}}$, OT-I, specific for a chicken ovalbumin-derived peptide (SIINFEKL) (19). A comparison of T cells $\left(\mathrm{CD}^{+}\right)$and B cells $\left(\mathrm{B} 220^{+}\right)$showed that the TN line had a relative increase in the $\mathrm{CD}^{+}$population $(35.6 \%$ for TN versus $12.8 \%$ for B6CF1 wildtype) and that this population consisted mainly of $\mathrm{CD}^{+} \mathrm{T}$ cells $\left(91.3 \%\right.$ for TN versus $43.1 \%$ for wildtype, Fig. $2 \mathrm{~B}$ ). A skewing in the CD8 ${ }^{+}$ population was also apparent in the OT-I line $(84.8 \%)$, but without a relative increase in $\mathrm{CD}^{+}$cells $(17.7 \%)$. The majority of $\mathrm{CD} 8^{+} \mathrm{TN}$ cells were $\mathrm{CD} 44^{\text {low }} \mathrm{CD}^{2} \mathrm{~L}^{+}$, indicative of a naïve phenotype (64.1\% for T57 versus $69.6 \%$ for wildtype). We also compared the TN line $\mathrm{G} 4$ to the transgenic line $2 \mathrm{C}$ (Fig. $2 \mathrm{C}$ ). The alloreactive $2 \mathrm{C}$ line was derived from a Balb/b mouse $\left(\mathrm{H}-2^{\mathrm{b}}\right)$ injected with $\mathrm{H}-2^{\mathrm{d}}$ cells $\left(\mathrm{H}-2^{\mathrm{b}}\right.$ anti H-2 $\left.{ }^{\mathrm{d}}\right)$. Its response against the QL9 peptide is particularly well characterized (20-22). Similar patterns were observed for the two TN lines G4 and T57. TN mice expressing only a single copy of a pre-rearranged endogenous $\beta$-chain had no major changes in T cell subsets, whereas TN mice expressing a single copy of a prerearranged endogenous $\alpha$-chain had an increase in $\mathrm{CD}^{+} \mathrm{CD}^{-} \mathrm{CD}^{-}$cells in the spleen (fig. S3A-B). Finally, we found that T cell development in TN mice T57 and G4 in all aspects examined resembles that of B6CF1 wildtype mice, and of some transgenic lines (fig. S4A-D, fig. S5A-B).

Because $\mathrm{TN} \mathrm{CD} 8^{+} \mathrm{T}$ cells were generated from freshly isolated effector $\mathrm{CD} 8^{+} \mathrm{T}$ cells, we hypothesized that TN T cells may have MHC binding characteristics distinct from conventional TCR transgenic mice. In a MHC-I-tetramer dissociation assay, the TN CD8 ${ }^{+} \mathrm{T}$ cells of $\mathrm{H}-2 \mathrm{~L}^{\mathrm{d}}$ haplotype dissociated faster from their cognate peptide-MHC-I complex than did transgenic $2 \mathrm{C}$ cells (Fig. $3 \mathrm{~A}$ ). The observed differences in dissociation rate of the $\mathrm{H}-2 \mathrm{~L}^{\mathrm{d}} \mathrm{T}$ cells are not due to differences in peptide-MHC interactions, since the peptides QL9, G4, and R7 stabilized $\mathrm{H}-2 \mathrm{~L}^{\mathrm{d}}$ in transporter of antigen processing (TAP)-deficient cells equally well (Fig. 3B). Although we are aware of the limitations of tetramer dissociation as a surrogate parameter for TCR affinity (23), we consider it possible that the average $T$. gondii-specific $\mathrm{H}-2 \mathrm{~L}^{\mathrm{d}}$-restricted TCR may well be of lower affinity than the highly selected $2 \mathrm{C}$. A comparison of TN T57 with transgenic OT-I cells showed similar dissociation rates (Fig. 3C). We examined the ability of TN CD8 ${ }^{+} \mathrm{T}$ cells to produce IFN- $\gamma$ upon stimulation with peptide-loaded antigenpresenting cells in vitro. TN T cells secreted IFN- $\gamma$ only when stimulated with the corresponding peptide (Fig. 3D).

To assess the extent to which the presence of only the TCR $\alpha$ - or $\beta$-chain suffices to yield TCRs of specificity similar to that of the TN $\alpha \beta$ pair, we analyzed mice that carry only the TN $\alpha$ - or only the TN $\beta$-chain of T57 or G4 (fig. S6A). There was no increase in tetramer-positive T cells in mice carrying the TN $\beta$-chain or $\alpha$-chain only.

We next compared the in vivo response of wildtype $\mathrm{BL} / 6$ and $\mathrm{TN} \mathrm{CD} 8^{+} \mathrm{T}$ cells to an infection with $T$. gondii (Fig. 4A-B, fig. S6B-E). In wildtype mice, we detect T57 tetramer-positive $\mathrm{CD} 8^{+} \mathrm{T}$ cells mainly between day 9 to 15 post infection, with a maximum frequency of about $7 \%$ (fig. S6B). When $\mathrm{T} 57 \mathrm{CD} 8^{+} \mathrm{T}$ cells were adoptively transferred into wildtype mice, the kinetics of expansion were comparable, but with a much higher frequency of T57 tetramerpositive $\mathrm{CD}^{+} \mathrm{TN}$ T cells (about $60 \%$ ) (Fig. 4A-B). We detected little or no response from the endogenous $\mathrm{CD}^{+} \mathrm{T}$ cells in these mice that received TN T cells (Fig4A, fig. S6C).

Similarly, when CFSE-labeled CD8 ${ }^{+} \mathrm{T}$ cells from wildtype or $\mathrm{T} 57$ mice were transferred into recipient mice and subsequently infected with $T$. gondii, upregulation of CD69 and dilution of CFSE was only observed in mice receiving T57 T cells (fig. S6D-E).

We next investigated the protective potential of $\mathrm{CD} 8^{+} \mathrm{T}$ cells from T57 TN mice. Animals infected with a lethal dose of $T$. gondii die around day 10 , and some of the $\mathrm{CD} 8^{+} \mathrm{T}$ cell responses do not peak before that time (15-17). When B6CF1 mice were challenged with a lethal dose 
of T. gondii, 4 out of 7 mice receiving CD8 ${ }^{+} \mathrm{T}$ cells from $\mathrm{T} 57 \mathrm{TN}$ mice survived the acute phase of infection, compared to 1 out of 7 in the control group (Fig. 4C). Using live imaging in the course of a lethal challenge with luciferase-expressing $T$. gondii, we observed a significant reduction in parasite load at day 7 post infection in the group that received CD8 ${ }^{+}$ T cells from T57 (Fig. 4D). Further experiments will show whether all five TN lines are equally capable of controlling $T$. gondii, and help establish the number of specific cells needed, as well as the cell type (naive, effector, or memory $\mathrm{T}$ cell) most effective at protection.

Transgenic mouse models have long been used to study various aspects of the immune system. Their generation involves long-term culture and repeated stimulation of $\mathrm{T}$ cells with antigen, isolation of the TCR $\alpha$ - and $\beta$-chains as cDNA or genomic fragments under the control of a non-endogenous promoter, and integration of the TCR into the mouse genome at nonhomologous sites (24-26). This inevitably leads to variation in expression levels, kinetics, and development even in mice expressing the same TCR (27). Further studies of suitable TCR transgenic lines are governed mostly by random selection of a "best responder". To show that somatic cells can be reprogrammed, a mouse line had been generated from a randomly chosen T cell (10). This mouse showed skewed T cell development, with a strong increase in the CD4CD8 DN population (45\% in LN3 compared to 5\% in wildtype), attributed to aberrant expression of the $\alpha$-chain (11). Besides a relative shift in the DN1-4 stages towards the DN4 phase, we did not observe an increase in the CD4-CD8 DN population in the TN mice reported here. TN mice have no additional experimentally introduced genetic modifications. Consequently, the differences observed amongst TN lines must be due to position effects within the rearranged TCR locus, or derive from the intrinsic properties of the expressed TCR. A comparison of different TN mouse lines might therefore allow a detailed dissection of these properties without the confounding effects of transgenic artifacts.

The time-consuming generation of transgenic mouse models has lead to the widespread use of a limited number of surrogate antigens, such as ovalbumin (recognized by the OT-I and OTII transgenic mice) to study the immunobiology of infectious disease. Pathogens engineered to produce fragments of ovalbumin, and the immune reaction against it, are unlikely to capture all essential aspects of the physiological response. As an example, we show that T57 TN $\mathrm{CD} 8^{+} \mathrm{T}$ cells proliferate upon infection with $\mathrm{T}$. gondii and significantly reduce the parasiteburden, but provide limited protection against an acute lethal challenge with $T$. gondii. Are responses against all epitopes equally protective? What is the best cell type to provide protection? Do responses against some epitopes protect from Toxoplasma-induced encephalitis? The answers to such questions require ready access to $\mathrm{T}$ cells that accurately reflect the natural response against the pathogen, and TN T cells arguably meet that requirement best. Taken together, transnuclear mice obtained by SCNT can be generated rapidly from freshly isolated specific $\mathrm{CD} 8^{+} \mathrm{T}$ cells. As long as methods for identification of antigen-specific lymphocytes can be applied, this strategy should also be applicable for $\mathrm{CD} 4^{+} \mathrm{T}$ cells and $\mathrm{B}$ cells. Transnuclear mice resemble a new type of mouse model, which express their TCR $\alpha-$ and $\beta$-chains from their endogenous loci under the control of their endogenous promoters without further genetic modification, thus avoiding genetic footprints at the site of integration, an unavoidable hallmark of transgenics.

\section{References and Notes}

1. Wong P, Pamer EG. Annu. Rev. Immunol 2003;21:29. [PubMed: 12414723]

2. Amanna IJ, Slifka MK, Crotty S. Immunol. Rev 2006;211:320. [PubMed: 16824139]

3. Harrington LE, Most Rv R, Whitton JL, Ahmed R. J. Virol 2002;76:3329. [PubMed: 11884558]

4. Gredmark-Russ S, Cheung EJ, Isaacson MK, Ploegh HL, Grotenbreg GM. J. Virol. 2008

5. Moutaftsi M, et al. Nat. Biotechnol 2006;24:817. [PubMed: 16767078]

6. Wakayama T, Yanagimachi R. Mol. Reprod. Dev 2001;58:376. [PubMed: 11241773] 
7. Kishigami S, et al. Biochem. Biophys. Res. Commun 2006;340:183. [PubMed: 16356478]

8. Eggan K, et al. Proc. Natl. Acad. Sci. U S A 2001;98:6209. [PubMed: 11331774]

9. Inoue K, et al. Curr. Biol 2005;15:1114. [PubMed: 15964276]

10. Hochedlinger K, Jaenisch R. Nature 2002;415:1035. [PubMed: 11875572]

11. Serwold T, Hochedlinger K, Inlay MA, Jaenisch R, Weissman IL. J. Immunol 2007;179:928. [PubMed: 17617584]

12. Koralov SB, Novobrantseva TI, Hochedlinger K, Jaenisch R, Rajewsky K. J. Exp. Med 2005;201:341. [PubMed: 15699070]

13. Suzuki Y, Remington JS. J. Immunol 1990;144:1954. [PubMed: 2106557]

14. Dzierszinski FS, Hunter CA. Parasite Immunol 2008;30:235. [PubMed: 18194347]

15. Frickel EM, et al. J. Infect. Dis. 2008

16. Wilson DC, et al. PLOS Pathogen. In Press.

17. Blanchard N, et al. Nat. Immunol 2008;9:937. [PubMed: 18587399]

18. Kishigami S, et al. J Reprod Dev 2007;53:165. [PubMed: 17077581]

19. Hogquist KA, et al. Cell 1994;76:17. [PubMed: 8287475]

20. Kranz DM, Sherman DH, Sitkovsky MV, Pasternack MS, Eisen HN. Proc. Natl. Acad. Sci. U S A 1984;81:573. [PubMed: 6607474]

21. Sha WC, et al. Nature 1988;336:73. [PubMed: 3263574]

22. Chen J, Eisen HN, Kranz DM. Microbes Infect 2003;5:233. [PubMed: 12681413]

23. Wang XL, Altman JD. J. Immunol. Methods 2003;280:25. [PubMed: 12972185]

24. Kouskoff V, Signorelli K, Benoist C, Mathis D. J. Immunol. Methods 1995;180:273. [PubMed: 7714342]

25. Pircher H, Burki K, Lang R, Hengartner H, Zinkernagel RM. Nature 1989;342:559. [PubMed: 2573841]

26. Mamalaki C, et al. Dev Immunol 1993;3:159. [PubMed: 8281031]

27. Barnden MJ, Allison J, Heath WR, Carbone FR. Immunol. Cell Biol 1998;76:34. [PubMed: 9553774]

28. Acknowledgements: The authors are thankful to H. Eisen, M.J. Gubbels, K. van Grinsven, E. Guillen, A. Drake, V. Mahajan, Q. Gao, and G. Yap for fruitful discussions and reagents. We are thankful to J. Dausman, R. Flannery, and J. Jackson for assistance with the management of the mouse colony. We are thankful to P. Wisniewski for FACSorting. We are thankful to J. Saeij and K. Jensen for the Pru PA7 and assistance with the in vivo imaging. EMF was supported by the Human Frontiers Science Program. RJ was supported by National Institute of Health grants RO1-HD045022 and R37CA084198. HLP was supported by grants from the National Institute of Health. A patent application has been filed. The sequences have been submitted to the EMBL Nucleotide Sequence Database, accession number FN601337-FN601346. 
A

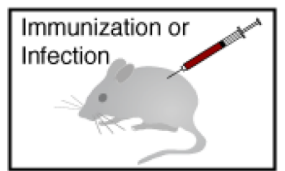

time [d] $\mid-x$

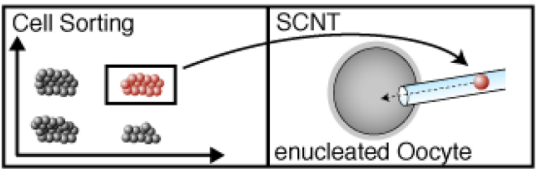

10

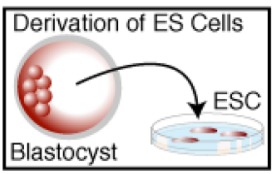

4-16

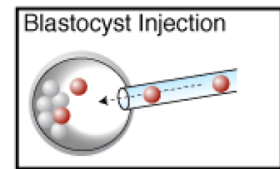

$\mid 20-25$

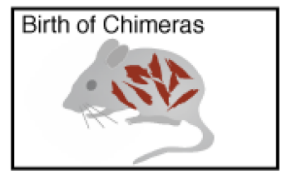

$\mid 37-42$
B

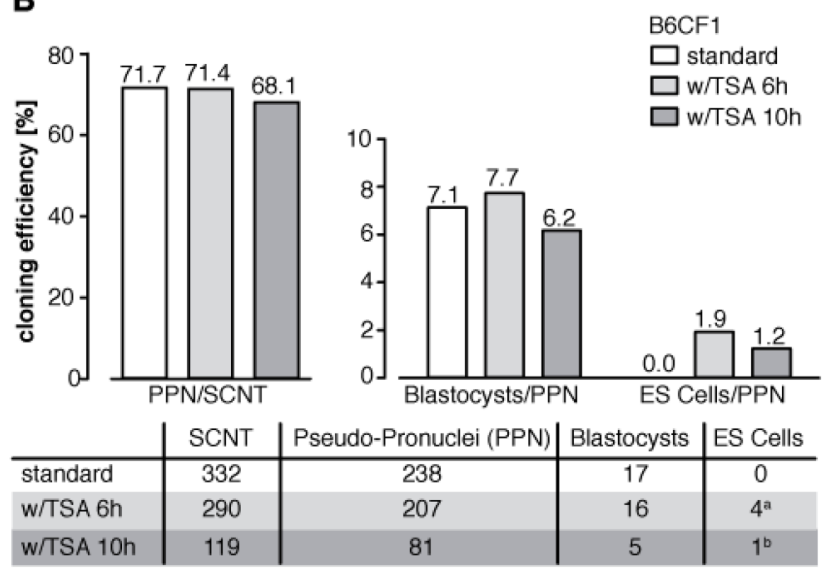

Resulting ESC lines: R7- $\left.\right|^{\mathrm{a}}, \mathrm{R} 7-1 \mathrm{I}^{\mathrm{a}}, \mathrm{R} 7-11^{\mathrm{a}}, \mathrm{T}^{\mathrm{a}} 7^{\mathrm{a}}$, and G4 ${ }^{\mathrm{b}}$

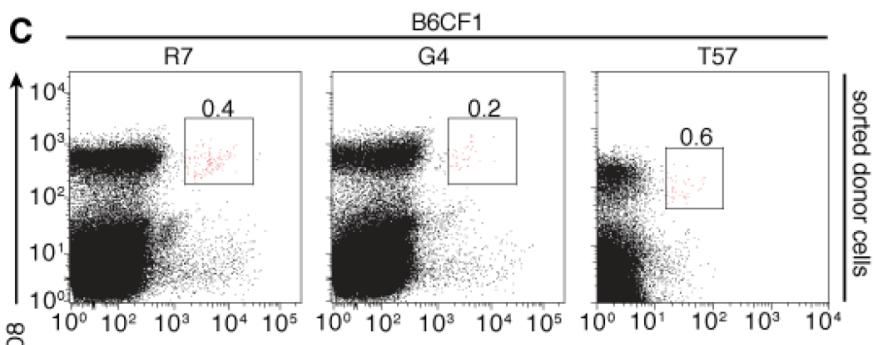

$\stackrel{\infty}{0}_{10}$

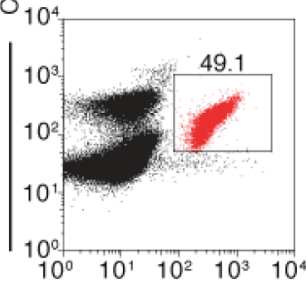

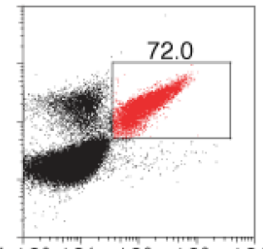

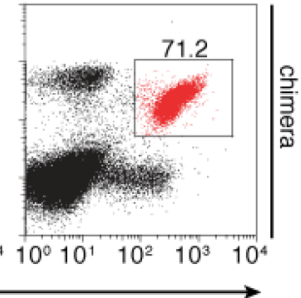

Fig. 1. SCNT of pre-defined $T$ cells

(A) Schematic representation of the underlying strategy and timeline. (B) Absolute and relative numbers of SCNT performed with $\mathrm{CD} 8^{+} \mathrm{T}$ cells and derived ES cells in B6CF1 background. (C) Top panels, representative flow cytometry plots of B6CF1 background mice infected with T. gondii. Gate and number (\% per total $\mathrm{CD} 8^{+} \mathrm{T}$ cells) indicates sorted $\mathrm{CD} 8^{+} \mathrm{T}$ cells with defined specificity used as donor cells. Lower panels, representative flow cytometry analysis of chimeric mice injected with SCNT-ESCs derived from according donor cells in top panel. Gate and number (\% per total $\mathrm{CD} 8^{+} \mathrm{T}$ cells) indicates the presence of specific $\mathrm{CD} 8^{+} \mathrm{T}$ cells in chimeric mice. 


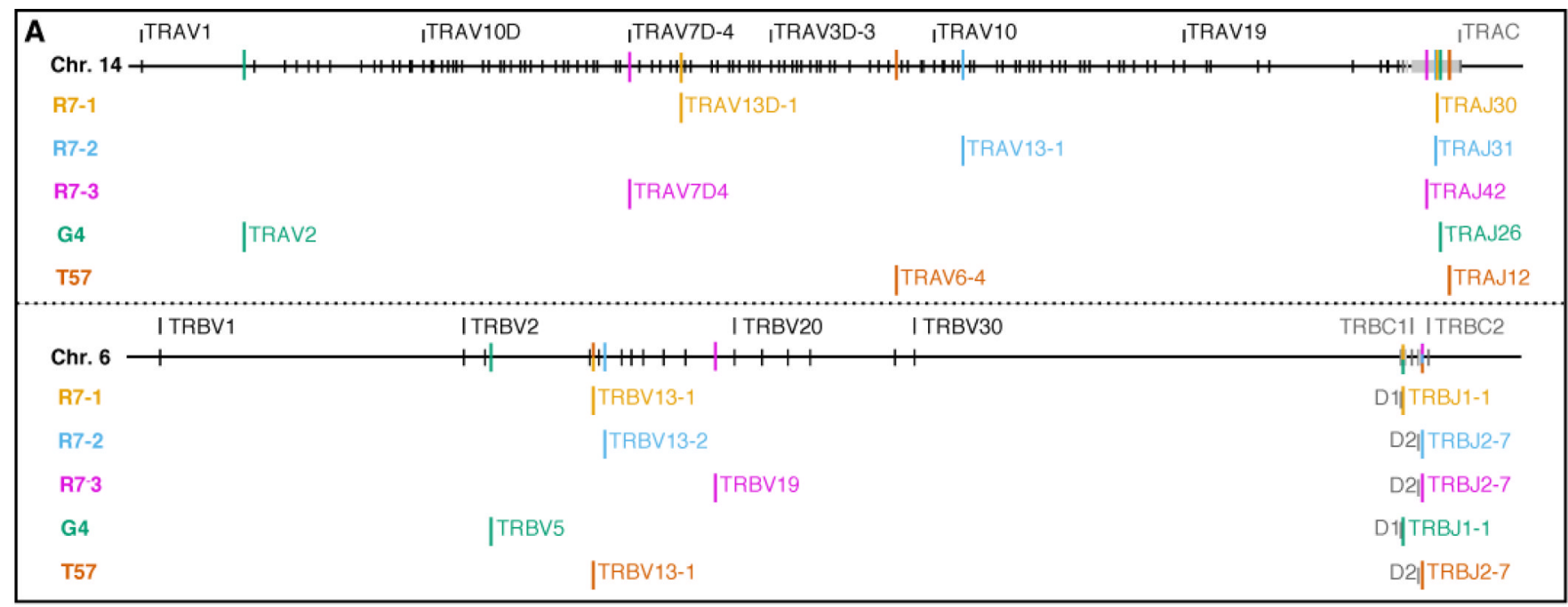

B
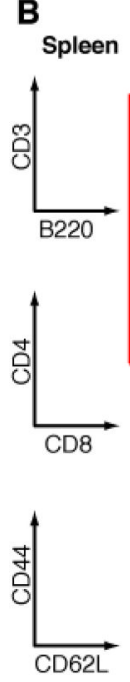
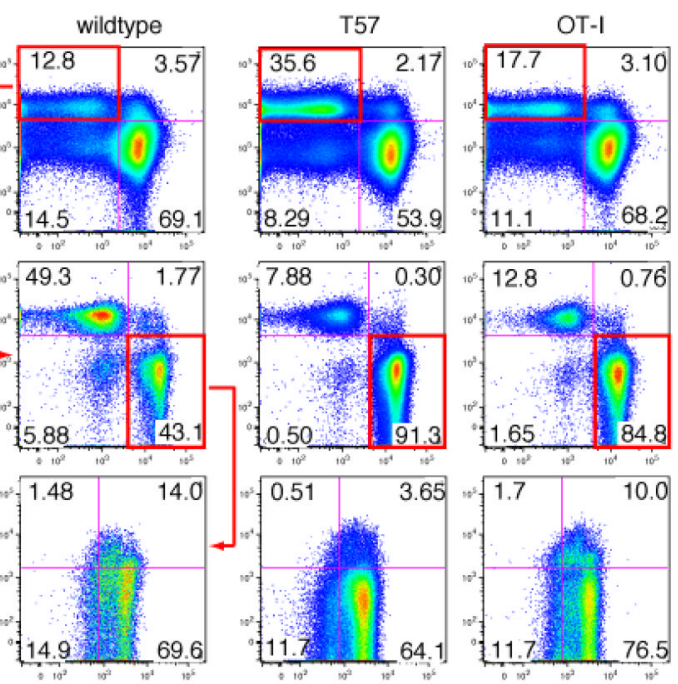

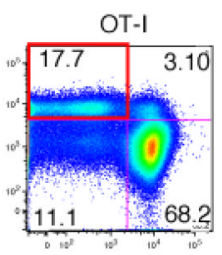

C

Spleen
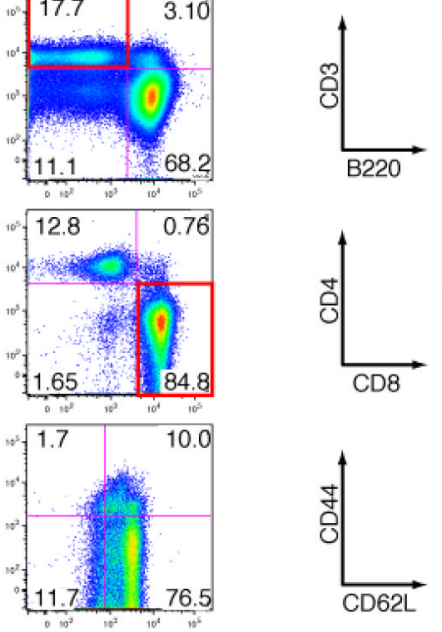
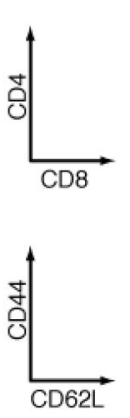
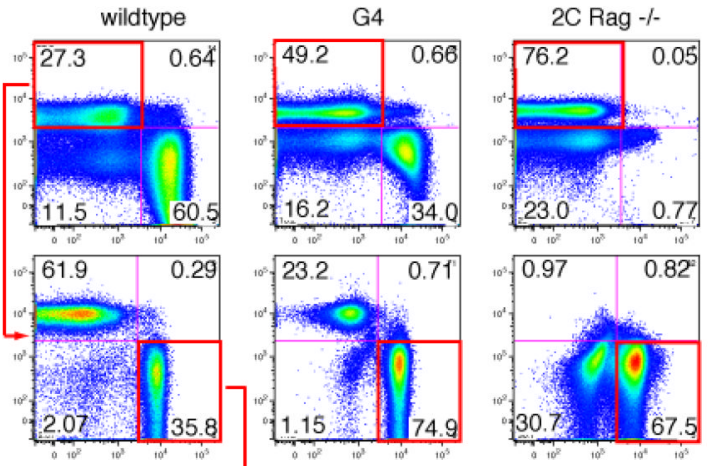

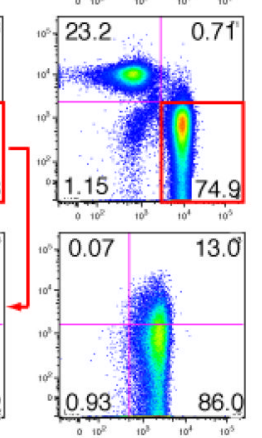

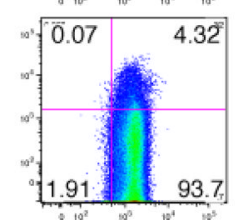

Fig. 2. TCR sequence and comparison of TN T cells with wildtype and transgenic mice

(A) Schematic representation of the V(D)J rearrangements at the TCR- $\alpha$ (top panel) and TCR$\beta$ locus (lower panel) in TN mice. Top row represents wildtype configuration and some regions for orientation (data based on www.ensembl.org). (B and C) Representative flow cytometric analysis of splenocytes from wildtype, T57 and OT-I mice (B) or wildtype, G4 and 2C $\mathrm{Rag}^{-/-}$mice (2 mice per genotype were analyzed) (C). 
A

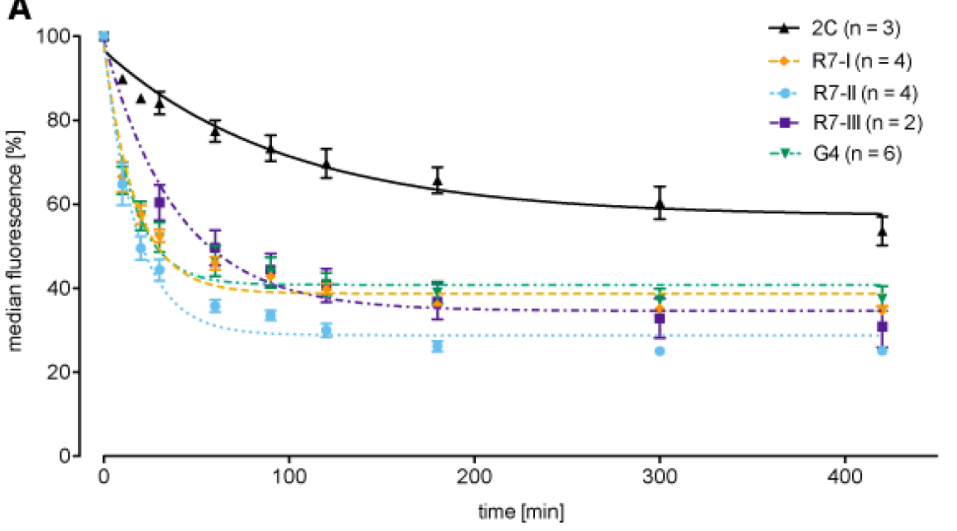

C

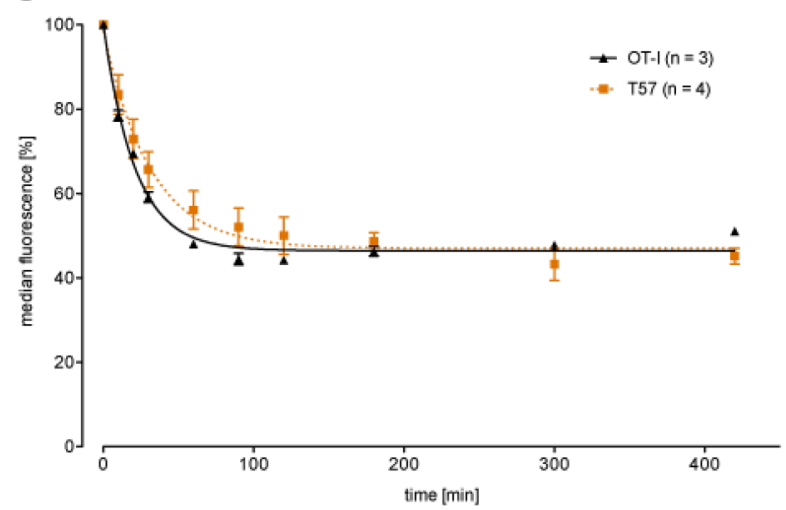

B

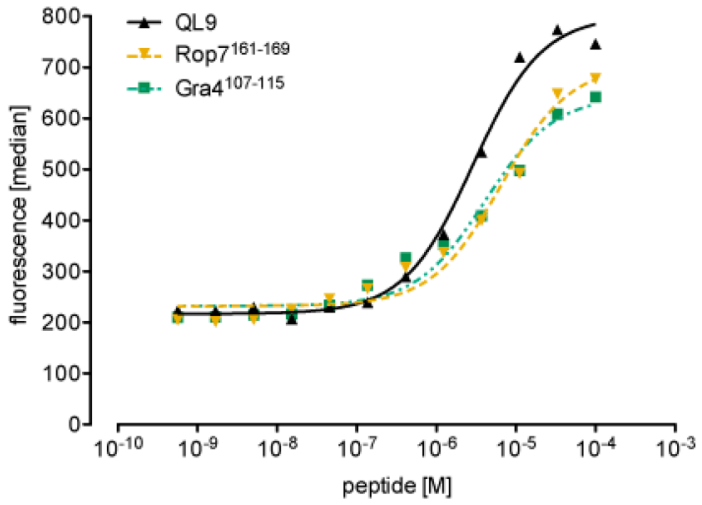

D $\quad \mathrm{T57}$

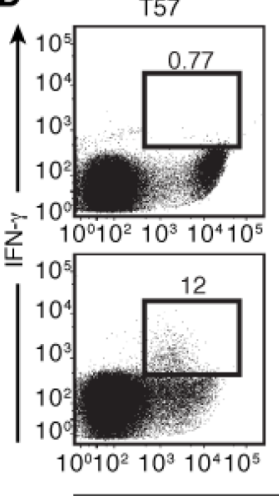

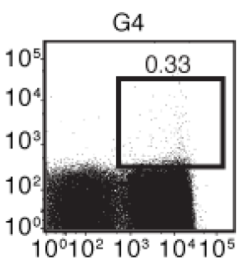

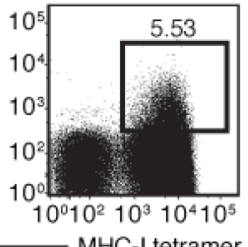

$10^{\circ} 10^{2} 10^{3} 10^{4} 10$
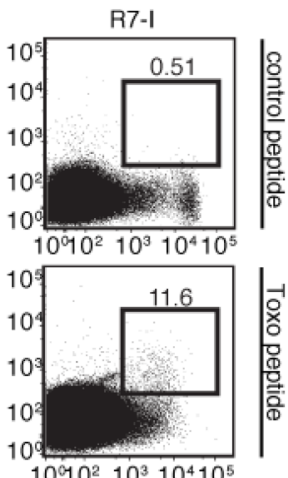

$10^{9} 0^{2} 10^{3} 10^{4} 10^{5}$

Fig. 3. TN T cell function in vitro

(A) Dissociation of peptide- $\mathrm{L}^{\mathrm{d}}$ tetramers from $\mathrm{CD}^{+} \mathrm{T}$ cells was measured for the transgenic line 2C $\mathrm{Rag}^{-/-}$(Ld-QL9) and the TN lines R7 I-III and G4 using flow cytometry and plotted over time. Number of repeats $(\mathrm{n})$ is shown in brackets. Data plotted represents mean \pm SEM. (B) Stabilization of $\mathrm{H}-2 \mathrm{~L}^{\mathrm{d}}$ on the surface of TAP-deficient cells via titration of QL9, R7 or G4 peptide (analyzed using Graphpad Prism software). (C) Dissociation of the peptide- $\mathrm{K}^{\mathrm{b}}$ tetramers from $\mathrm{CD}^{+} \mathrm{T}$ cells for the transgenic line OT-I and the TN line T57. Number of repeats (n) is shown in brackets. Data plotted is mean \pm SEM. (D) Flow cytometry analysis of IFN- $\gamma$ secretion upon stimulation of TN T cells with antigen presenting cells loaded with control peptide (upper panel) or corresponding specific peptide (lower panel). 
A
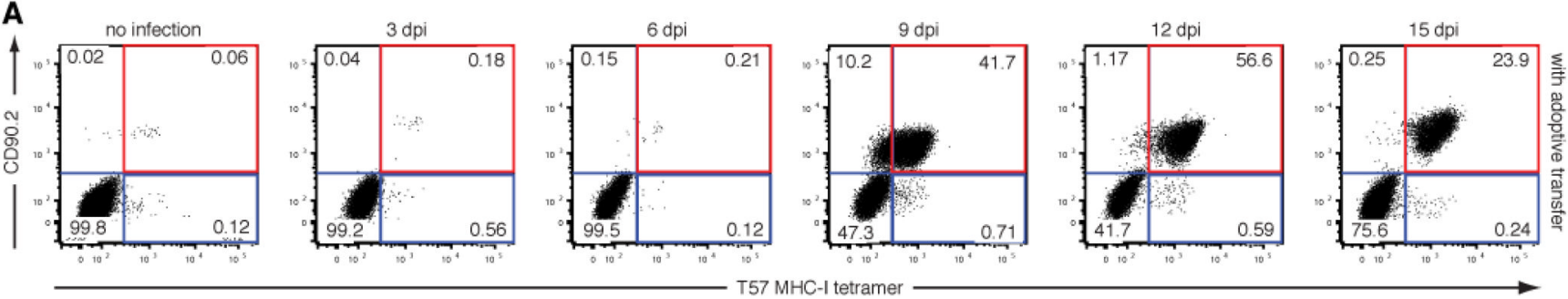

B

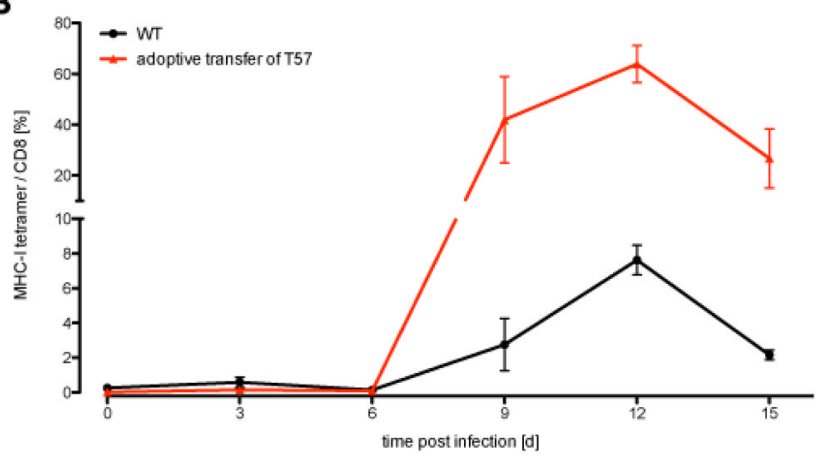

C

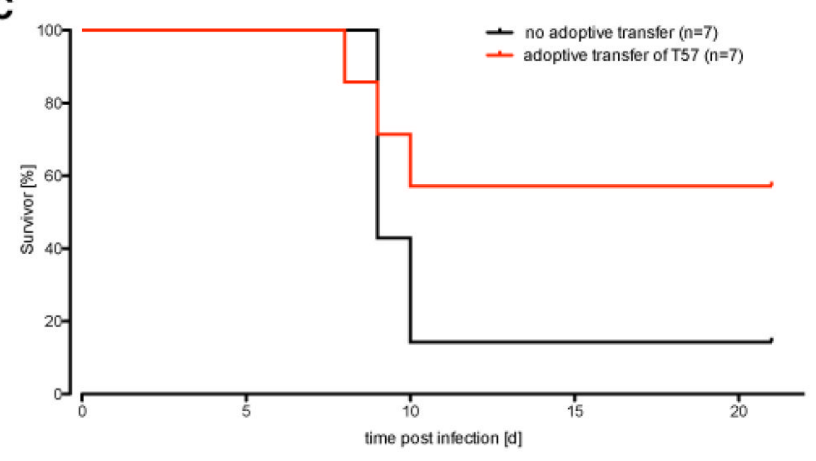

D
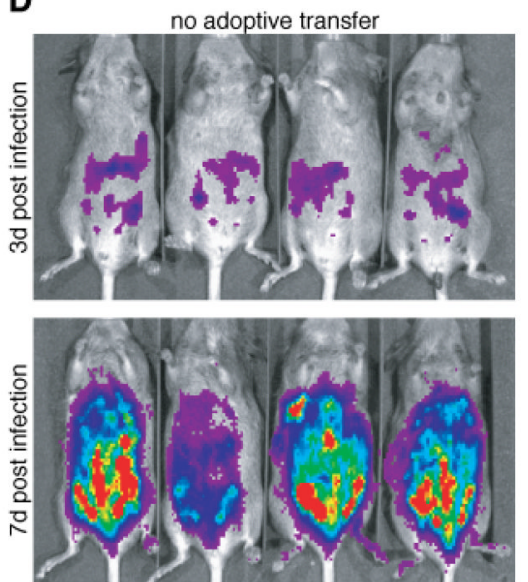
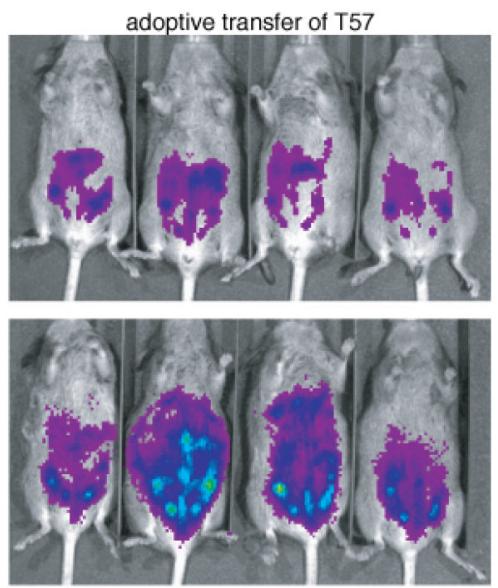
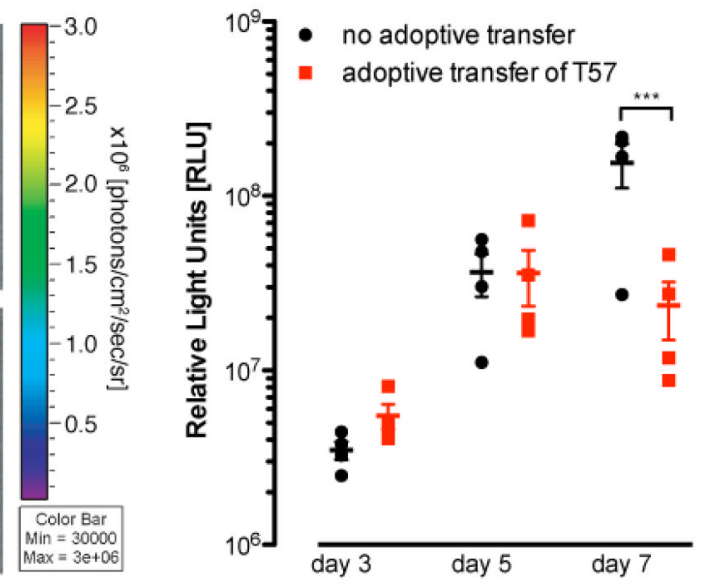

Fig. 4. TN T57 $\mathrm{T}$ cell function in vivo

(A) In vivo response of wildtype BL/6 mice having received an adoptive transfer of TN T57 $\mathrm{CD} 8^{+}$cells (3 mice per time point per group). Representative flow cytometric analysis at different time points post infection, with the boxes showing the percentage of T57-specific cells among $\mathrm{CD}^{+} \mathrm{T}$ cells. TN cells (red boxes) and endogenous cells (blue boxes) can be distinguished using CD90.2. (B) Graphical representation of the flow cytometric results showing the kinetics of wildtype (black curve), and TN (red curve) T57-specific CD8+ T cells (analyzed using Graphpad Prism software). (C) Survival curve of wildtype B6CF1 mice infected with lethal dose of tachyzoites ( $\mathrm{n}=7$ mice for each group). (D) Optical imaging of luciferase-expressing $T$. gondii during a lethal challenge (left panel) and quantification of signal (right panel) ( $\mathrm{n}=4$ mice per group). Data plotted are mean \pm SEM. $* * *$ indicates significant difference (2-way ANOVA, p-value < 0.001). 